\title{
Bone Health in Adult Men and Women with a History of Juvenile Idiopathic Arthritis
}

\author{
JUDITH THORNTON, STEPHEN R. PYE, TERENCE W. O'NEILL, DAVID RAWLINGS, ROGER M. FRANCIS, \\ DEBORAH P.M. SYMMONS, DARREN M. ASHCROFT, and HELEN E. FOSTER
}

\begin{abstract}
Objective. Our aim was to determine areal bone mineral density $\left(\mathrm{BMD}_{\mathrm{a}}\right)$ and disease-related factors linked with $\mathrm{BMD}_{\mathrm{a}}$ in adults with a history of juvenile idiopathic arthritis (JIA).

Methods. Men and women with a history of JIA attending a young adult rheumatology clinic in Newcastle, UK, underwent dual energy x-ray absorptiometry (DEXA) of the lumbar spine and total hip. Information was obtained about disease duration and subtype, previous treatment including corticosteroid and methotrexate therapy, and large-joint replacement. Subjects completed the modified Health Assessment Questionnaire (HAQ). Blood was taken for assessment of C-reactive protein, erythrocyte sedimentation rate, and rheumatoid factor (RF).

Results. Seventy-one women and 16 men, mean age 28.7 and 31.4 years, and mean disease duration 20.6 and 24.0 years, respectively, were studied. Mean $\mathrm{BMD}_{\mathrm{a}}$ was 0.982 (Z-score $=-0.328$; $95 \% \mathrm{CI}$ $-0.657,0.001)$ and $1.028 \mathrm{~g} / \mathrm{cm}^{2}(\mathrm{Z}$-score $=-0.251 ; 95 \% \mathrm{CI}-1.266,0.764)$ in women and men, respectively, at the spine and 0.817 (Z-score $=-0.542 ; 95 \% \mathrm{CI}-0.975,-0.109)$ and $0.857 \mathrm{~g} / \mathrm{cm}^{2}$ (Z-score $=$ $-0.176 ; 95 \% \mathrm{CI}-2.323,1.971)$ at the hip. After adjusting for age and sex, increasing HAQ score was associated with both lower spine $\mathrm{BMD}_{\mathrm{a}}$ and hip $\mathrm{BMD}_{\mathrm{a}}$. Compared with patients with oligoarticular disease, those with enthesitis-related arthritis had higher $\mathrm{BMD}_{\mathrm{a}}$ at the spine, while those with extended oligoarticular and polyarticular RF-negative disease had lower hip $\mathrm{BMD}_{\mathrm{a}}$. Oral corticosteroids and the presence of a large-joint replacement were associated with lower $\mathrm{BMD}_{\mathrm{a}}$ at both the spine and hip.

Conclusion. There was a trend toward low $\mathrm{BMD}_{\mathrm{a}}$ in women with a history of JIA. These patients may be at risk of the complications of osteoporosis including fragility fractures and should be considered for targeted preventive measures. (First Release June 15 2011; J Rheumatol 2011;38:1689-93; doi:10.3899/jrheum.101232)
\end{abstract}

\section{Key Indexing Terms: \\ JUVENILE IDIOPATHIC ARTHRITIS FRACTURE}

Juvenile idiopathic arthritis (JIA) is a chronic inflammatory disease of childhood. It is associated with decreased areal bone mineral density $\left(\mathrm{BMD}_{\mathrm{a}}\right)^{1,2,3,4,5,6}$. Known risk factors for low $\mathrm{BMD}_{\mathrm{a}}$ and fragility fractures in children with JIA include the inflammatory process ${ }^{7}$, nutrition ${ }^{8}$, growth impairment ${ }^{9}$, reduced physical activity ${ }^{8}$, and treatment, especially corticosteroids $^{5,10}$. Children with a mean duration of systemic onset JIA of 10.2 years attending Great Ormond Street Hospital, London, $\mathrm{UK}$, had lumbar spine $\mathrm{BMD}_{\mathrm{a}}$ assessments that were

From the Arthritis Research UK Epidemiology Unit, The University of Manchester, Manchester Academic Health Science Centre; School of Pharmacy and Pharmaceutical Sciences, The University of Manchester, Manchester Academic Health Science Centre, Manchester; Regional Medical Physics Department, Freeman Hospital; Institute for Ageing and Health, Newcastle University, Campus for Ageing and Vitality; Newcastle Hospitals NHS Trust, Newcastle University, Institute of Cellular Medicine, Newcastle upon Tyne, UK.

Support from the UK Department of Health through its Health Technology Assessment Programme and Arthritis Research UK.

J. Thornton, PhD, Research Associate; S.R. Pye, MPhil, Research Associate; T.W. O'Neill, MD, Reader in Rheumatology and Epidemiology, Arthritis Research UK Epidemiology Unit, The University of Manchester, Manchester Academic Health Science Centre; D. Rawlings, MPhil, Clinical Scientist, Regional Medical Physics Department, Freeman Hospital; R.M. Francis, FRCP, Professor of Geriatric Medicine and Honorary Consultant Physician, Institute for Ageing and Health,

\section{AREAL BONE MINERAL DENSITY RISK FACTORS}

on average $2 \mathrm{SD}$ lower than expected ${ }^{11}$. Reduced $\mathrm{BMD}_{\mathrm{a}}$ is associated with an increased risk of fractures. Data from the UK General Practice Research Database showed that a higher proportion of children with arthritis experienced fractures compared with a control group during a median followup of 3.9 years $(6.7 \% \text { vs } 3.3 \%)^{12}$.

JIA can persist into adulthood, but few studies have followed bone health beyond childhood $7,13,14,15$. An understanding of bone health and factors influencing bone health in

Newcastle University, Campus for Ageing and Vitality; D.P.M. Symmons, MD, Professor of Rheumatology \& Musculoskeletal Epidemiology; Arthritis Research UK Epidemiology Unit, The University of Manchester, Manchester Academic Health Science Centre; D.M. Ashcroft, PhD, Reader, School of Pharmacy and Pharmaceutical Sciences, The University of Manchester, Manchester Academic Health Science Centre; H.E. Foster, MD, Cert Med Ed, Professor of Paediatric Rheumatology and Honorary Consultant Paediatric and Adolescent Rheumatologist, Newcastle Hospitals NHS Trust, Newcastle University, Institute of Cellular Medicine.

Address correspondence to Dr. T.W. O'Neill, Arthritis Research UK Epidemiology Unit, The University of Manchester, Oxford Road, Manchester M13 9PT, United Kingdom.

E-mail:terence.o'neill@manchester.ac.uk

Full Release Article. For details see Reprints/Permissions at jrheum.org Accepted for publication April 4, 2011.

Personal non-commercial use only. The Journal of Rheumatology Copyright @ 2011 . All rights reserved. 
adults with a history of JIA is important, as reduced bone mass may lead to an increased risk of fracture in later life. Further, a knowledge of factors influencing bone mass is an important first step in developing strategies to optimize bone.

We examined a series of UK patients with a history of JIA who attended a young adult rheumatology clinic. Our aims were to determine the $\mathrm{BMD}_{\mathrm{a}}$ in affected individuals and to assess disease-related factors linked with $\mathrm{BMD}_{\mathrm{a}}$.

\section{MATERIALS AND METHODS}

Patients. Consecutive men and women with a history of JIA attending a young adult rheumatology clinic in Newcastle upon Tyne, UK, between 1996 and 2002, were included in the analysis. All patients were seen by the same rheumatologist and assigned a JIA subtype according to the International League of Associations for Rheumatology classification ${ }^{16}$. The patient group and the JIA young adult clinic have been described ${ }^{17}$.

Data collection. Dual energy x-ray absorptiometry (DEXA) of the lumbar spine (L1-L4) and hip was performed as part of routine clinical assessment. All scans were done between 1996 and 2002 on either a Hologic 4500A or Hologic QDR 2000 scanner (Bedford, Massachusetts, USA). Each machine was subject to maintenance and regular quality assurance and testing in accordance with the manufacturer's recommendations. Results were recorded as $\mathrm{BMD}_{\mathrm{a}}\left(\mathrm{g} / \mathrm{cm}^{2}\right)$ and as an age-standardized or Z-score (the number of SD an observed measurement is from the mean value for an individual of the same age and sex, calculated using the manufacturer's normative data).

As part of routine clinical practice at the time, all clinic attendees completed a modified Health Assessment Questionnaire (HAQ) and had blood taken for erythrocyte sedimentation rate (ESR), C-reactive protein (CRP), and rheumatoid factor (RF) estimation. Height and weight were recorded at the time of the scan. Clinical records were reviewed within 6 months of the DEXA scan date and often involved retrieval of case notes from many years previously. Information was obtained about disease subtype, disease duration, and current and previous treatment with oral corticosteroids (ever/never). In addition, data were recorded on duration of treatment (months), treatment with methotrexate (yes/no), and large-joint replacement (hip or knee, yes/no). Because this was an audit of clinical practice, all data were anonymous and informed consent was not required.

Analysis. Body mass index was calculated [weight $(\mathrm{kg}) /$ height $\left.(\mathrm{m})^{2}\right]$. The associations between putative disease-related risk factors and $\mathrm{BMD}_{\mathrm{a}}$ at both the spine and hip were examined using linear regression, with adjustments made for age and sex. The results were expressed as B coefficients and 95\% CI. Analysis was undertaken using STATA version 9.2 (http://stata.com).

\section{RESULTS}

Subjects. Of the 130 patients with a history of JIA who attended the young adult rheumatology clinic, 98 had bone densitometry done of the spine and hip. Eleven of them (3 men and 8 women) were excluded from our study because of missing DEXA data. That left 87 patients for our analysis. The characteristics of these patients are summarized in Table 1. There were 71 women and 16 men; mean age at scan was 28.7 (SD $10.1)$ and 31.4 (SD 13.8) years, respectively, and mean disease duration was 20.6 (SD 11.0) and 24.0 (SD 13.6) years, respectively. Fifty-one percent of the patients had ever received oral corticosteroids and $29 \%$ had taken methotrexate. Some patients had a history of polyarticular RF-negative disease (26\%); $21 \%$ had polyarticular RF-positive disease, $17 \%$ oligoarticular disease, $14 \%$ systemic disease, $9 \%$ extended oligoarticular disease, $6 \%$ psoriasis, $5 \%$ enthesitis-related dis- ease, and 2\% other. One in 4 had had either hip or knee arthroplasty. The mean ESR at the time of assessment was $23 \mathrm{~mm} / \mathrm{h}$, and CRP was $19.2 \mathrm{mg} / \mathrm{l}$.

Bone mineral density. Mean $(95 \% \mathrm{CI}) \mathrm{BMD}_{\mathrm{a}}$ was 0.982 $(0.947,1.018)$ and $1.028(0.910,1.146) \mathrm{g} / \mathrm{cm}^{2}$ in women and men, respectively, at the lumbar spine and $0.817(0.761$, $0.874)$ and $0.857(0.665,1.050) \mathrm{g} / \mathrm{cm}^{2}$ at the hip (Table 2). In women, the mean Z-score at the spine was -0.328 , and at the hip, -0.542 , a value significantly lower than would be expected in a normal population $(\mathrm{p}<0.02)$. In men, mean Z-scores were -0.251 at the spine and -0.176 at the hip. Increasing age was significantly associated with $\mathrm{BMD}_{\mathrm{a}}$ at the spine. $\mathrm{BMD}_{\mathrm{a}}$ was lower in women compared to men at both spine and hip, although $\mathrm{CI}$ embraced unity. After adjusting for age and sex, increasing weight and height were associated with a higher $\mathrm{BMD}_{\mathrm{a}}$ at both the spine and hip (Table 3). Increasing physical disability (HAQ score) was associated with both a lower spine and hip $\mathrm{BMD}_{\mathrm{a}}$. Compared with oligoarticular disease, those with enthesitis-related arthritis had a higher lumbar spine $\mathrm{BMD}_{\mathrm{a}}$, while those with extended oligoarticular disease and polyarticular RF-negative disease had lower hip $\mathrm{BMD}_{\mathrm{a}}$. Treatment with oral corticosteroids was associated with a lower lumbar spine and hip $\mathrm{BMD}_{\mathrm{a}}$, as was having a large-joint arthroplasty (hip or knee).

\section{DISCUSSION}

In our study, there was a trend toward a low $\mathrm{BMD}_{\mathrm{a}}$, particularly at the hip, in women with a history of JIA. BMD $\mathrm{Bas}_{\mathrm{a}}$ was reduced particularly among patients with more severe disease as determined by disease subtype and level of function.

Ours is the first UK study to examine the effect of disease-related factors on bone health in adults with a history of JIA. It was a retrospective review of clinical practice at the time and accordingly, as with many such clinical outcome studies reliant on retrospective case note analysis, there are a number of limitations to consider. While all patients attending the clinic were offered a bone density scan, about $25 \%$ did not subsequently keep the appointment. It is possible that these patients may have differed with respect to bone mass levels from those who had a scan. Their omission may have resulted in an overestimate or underestimate of bone mass levels in the group, and the data need to be interpreted with some caution. It should not have influenced, however, the analysis of disease factors influencing bone mass that was based on an internal analysis of responders. The data concerning disease characteristics, including treatment, were obtained from clinical records and therefore subject to recording errors. Because little information on dose or duration of corticosteroid treatment was available, the analysis of corticosteroid use was restricted to comparison of patients who had ever received or never received corticosteroids. Recording was incomplete for other risk factors for osteoporosis, for example, smoking and drinking habits. The DEXA scans were performed as part of routine clinical practice and on a separate date (invariably within 6

Personal non-commercial use only. The Journal of Rheumatology Copyright @ 2011 . All rights reserved. 
Table 1. Demographic and disease-related characteristics. All data are mean (SD) or $\mathrm{n}(\%)$.

\begin{tabular}{|c|c|c|c|}
\hline Characteristics & Women, $\mathrm{n}=71$ & Men, $\mathrm{n}=16$ & Overall, $\mathrm{n}=87$ \\
\hline Age, yrs & $28.7(10.1)$ & $31.4(13.8)$ & $29.2(10.8)$ \\
\hline Height, $m$ & $1.6(0.1)$ & $1.7(0.1)$ & $1.6(0.9)$ \\
\hline Weight, $\mathrm{kg}$ & $60.2(16.0)$ & $67.6(18.6)$ & $61.5(16.7)$ \\
\hline Body mass index, $\mathrm{kg} / \mathrm{m}^{2}$ & $23.4(5.3)$ & $24.1(6.2)$ & $23.5(5.5)$ \\
\hline Disease duration, yrs & $20.6(11.0)$ & $24.0(13.6)$ & $21.2(11.5)$ \\
\hline Current smoker & $16(22.5)$ & $2(22.2)$ & $18(22.5)$ \\
\hline \multicolumn{4}{|l|}{ Disease characteristics and treatment } \\
\hline \multicolumn{4}{|l|}{ Disease subtype (ILAR) } \\
\hline Systemic & $7(9.9)$ & $5(1.3)$ & $12(13.8)$ \\
\hline Oligoarticular & $12(16.9)$ & $3(18.8)$ & $15(17.2)$ \\
\hline Extended oligoarticular & $8(11.3)$ & 0 & $8(9.2)$ \\
\hline Polyarticular RF-positive & $17(23.9)$ & $1(6.3)$ & $18(20.7)$ \\
\hline Polyarticular RF-negative & $21(29.6)$ & $2(12.5)$ & $23(26.4)$ \\
\hline Psoriasis & $3(4.2)$ & $2(12.5)$ & $5(5.8)$ \\
\hline Enthesitis-related & $2(2.8)$ & $2(12.5)$ & $4(4.6)$ \\
\hline Other & $1(1.41)$ & $1(6.3)$ & $2(2.3)$ \\
\hline RF-positive & $21(29.6)$ & $1(6.3)$ & $22(25.3)$ \\
\hline HAQ score $(0-3)$ & $1.3(0.8)$ & $1.5(0.8)$ & $1.3(0.8)$ \\
\hline $\mathrm{ESR}, \mathrm{mm} / \mathrm{h}$ & $23.2(20.0)$ & $21.0(26.3)$ & $23.0(20.5)$ \\
\hline $\mathrm{CRP}, \mathrm{mg} / \mathrm{l}$ & $17.8(20.9)$ & $26.3(29.2)$ & $19.2(22.3)$ \\
\hline Large-joint arthroplasty (yes vs no) & $16(22.5)$ & $4(66.7)$ & $20(26.0)$ \\
\hline Hip arthroplasty (yes vs no) & $15(21.1)$ & $4(66.7)$ & $19(24.7)$ \\
\hline Knee arthroplasty (yes vs no) & $12(16.9)$ & $4(66.7)$ & $16(20.8)$ \\
\hline Methotrexate (ever, yes vs no) & $20(29.0)$ & $2(25.0)$ & $22(28.6)$ \\
\hline Other DMARD (ever, yes vs no) & $33(46.5)$ & $6(37.5)$ & $39(44.8)$ \\
\hline Oral steroids (ever, yes vs no) & $34(49.3)$ & $5(62.5)$ & $39(50.7)$ \\
\hline Duration of oral steroids, mo & $76.3(90.1)$ & $19.0(24.0)$ & $72.9(88.5)$ \\
\hline
\end{tabular}

ILAR: International League of Associations for Rheumatology; RF: rheumatoid factor; HAQ: Health Assessment Questionnaire; ESR: erythrocyte sedimentation rate; CRP: C-reactive protein; DMARD: disease-modifying antirheumatic drug.

Table 2. Areal bone mineral density $\left(\mathrm{BMD}_{\mathrm{a}}\right)$ and $\mathrm{Z}$-score at the lumbar spine and total hip. Data are mean $(95 \% \mathrm{CI})$.

\begin{tabular}{lcc}
\hline & Women & Men \\
\hline BMD $_{\mathrm{a}}$ & & \\
$\quad$ Lumbar spine, $\mathrm{g} / \mathrm{cm}^{2}$ & $0.982(0.947,1.018)$ & $1.028(0.910,1.146)$ \\
$\quad$ Total hip, g/cm & $0.817(0.761,0.874)$ & $0.857(0.665,1.050)$ \\
Z-score & & \\
$\quad$ Lumbar spine & $-0.328(-0.657,0.001)$ & $-0.251(-1.266,0.764)$ \\
$\quad$ Total hip & $-0.542(-0.975,-0.109)$ & $-0.176(-2.323,1.971)$ \\
\hline
\end{tabular}

months of the clinical notes reviews and clinic assessment). Finally, the subjects included in the analysis were those who were attending an adult continuity rheumatology clinic and who were therefore likely to have had more severe disease; results should be extrapolated beyond this group with caution.

Our data are consistent with previous studies that reported that $\mathrm{BMD}_{\mathrm{a}}$ was low in adults with JIA $\mathrm{A}^{7,13,14,15}$. A cohort of 32 adults with JIA was followed retrospectively for a mean of 27.1 years; a greater proportion were osteopenic at the femoral neck than would have been expected ${ }^{14}$. In a case-control study, 65 adult patients (mean age 32.2 years) with a history of JIA were compared with healthy control subjects matched for age, sex, height, and weight. $\mathrm{BMD}_{\mathrm{a}}$ at the hip and lumbar spine were significantly lower in both men and women with JIA compared with matched healthy control subjects ${ }^{13}$. Subsequent linear regression with group (JIA or control) as the only predictor confirmed that JIA was strongly associated with hip or spine $\mathrm{BMD}_{\mathrm{a}}(\mathrm{p}<0.001)$, explaining about $20 \%$ of the variation in outcome ${ }^{13}$. Haugen, et al followed 229 adults with JIA ${ }^{7}$. The mean followup since diagnosis was 15.6 years in women and 14.9 years in men. Men and women with persistent JIA had significantly reduced $\mathrm{BMD}_{\mathrm{a}}$ at the femoral neck, total body, and radius and lumbar spine compared with healthy subjects ${ }^{7}$. In 26 young women with JIA, BMD (mea- $^{-}$ sured using dual photon absorptiometry) was lower than expected in $23 \%$ of patients 15 .

There is some evidence in the literature that disease activity is associated with reduced bone mass in adults with JIA. Zak, et al noted that active disease and spine erosions at baseline were associated with significantly reduced spine $\mathrm{BMD}_{\mathrm{a}}$ at followup ${ }^{13}$. In contrast, French, et al, found no association with disease activity as measured by joint count ${ }^{14}$. Haugen, et al differentiated subjects with active disease and those in remission ${ }^{7}$. Men and women with persistent disease activity had reduced $\mathrm{BMD}_{\mathrm{a}}$, while men in remission had $\mathrm{BMD}_{\mathrm{a}}$ similar to controls and women had a similar $\mathrm{BMD}_{\mathrm{a}}$ to controls at the spine, although $\mathrm{BMD}_{\mathrm{a}}$ was significantly reduced at the

$$
\text { Personal non-commercial use only. The Journal of Rheumatology Copyright @ } 2011 \text {. All rights reserved. }
$$


Table 3. Influence of disease-related factors on areal bone mineral density $\left(\mathrm{BMD}_{\mathrm{a}}\right)$ at the lumbar spine and total hip. Results are expressed as $ß$-coefficient $(95 \% \mathrm{CI})$ adjusted for age and sex.

\begin{tabular}{|c|c|c|}
\hline & $\begin{array}{l}\text { Lumbar Spine BMD } \\
\qquad\left(\mathrm{g} / \mathrm{cm}^{2}\right)\end{array}$ & $\begin{array}{l}\text { Total Hip BMD } \\
\qquad\left(\mathrm{g} / \mathrm{cm}^{2}\right)\end{array}$ \\
\hline Weight, kg & $0.005(0.003,0.007)^{*}$ & $0.006(0.003,0.009)^{*}$ \\
\hline Height, cm & $0.007(0.004,0.011)^{*}$ & $0.012(0.005,0.019)^{*}$ \\
\hline Age at scan, yrs & $0.004(0.001,0.007)^{*}$ & $0.000(-0.006,0.006)$ \\
\hline $\operatorname{Sex}(\mathrm{F}$ vs $M)$ & $-0.046(-0.136,0.045)$ & $-0.040(-0.195,0.114)$ \\
\hline Disease duration, yrs & $-0.005(-0.011,0.001)$ & $-0.004(-0.015,0.006)$ \\
\hline HAQ score $(0-3)$ & $-0.099(-0.148,-0.051)^{*}$ & $-0.122(-0.217,-0.026)^{*}$ \\
\hline $\mathrm{ESR}, \mathrm{mm} / \mathrm{h}$ & $0.000(-0.002,0.003)$ & $0.002(-0.004,0.007)$ \\
\hline \multicolumn{3}{|l|}{$\mathrm{ESR}, \mathrm{mm} / \mathrm{h}$} \\
\hline$<20$ & Referent & Referent \\
\hline$\geq 20$ & $-0.007(-0.110,0.097)$ & $0.057(-0.142,0.255)$ \\
\hline CRP, mg/l & $-0.001(-0.004,0.001)$ & $-0.001(-0.005,0.003)$ \\
\hline RF-positive (yes vs no) & $0.023(-0.058,0.103)$ & $0.057(-0.065,0.178)$ \\
\hline \multicolumn{3}{|l|}{ Disease subtype } \\
\hline Oligoarticular & Referent & Referent \\
\hline Systemic & $-0.108(-0.222,0.007)$ & $-0.180(-0.382,0.022)$ \\
\hline Extended oligoarticular & $-0.034(-0.167,0.098)$ & $-0.280(-0.496,-0.064)^{*}$ \\
\hline Polyarticular RF-positive & $-0.101(-0.205,0.003)$ & $-0.098(-0.266,0.070)$ \\
\hline Polyarticular RF-negative & $-0.090(-0.190,0.009)$ & $-0.184(-0.343,-0.025)^{*}$ \\
\hline Psoriasis & $0.036(-0.116,0.188)$ & $0.074(-0.154,0.302)$ \\
\hline Enthesitis-related & $0.212(0.044,0.379)^{*}$ & $0.053(-0.226,0.333)$ \\
\hline Other & $-0.062(-0.287,0.163)$ & $0.072(-0.267,0.411)$ \\
\hline Oral corticosteroids (yes vs no) & $-0.143(-0.211,-0.075)^{*}$ & $-0.136(-0.248,-0.024)^{*}$ \\
\hline Methotrexate (yes vs no) & $-0.071(-0.154,0.013)$ & $0.015(-0.112,0.143)$ \\
\hline Large-joint replacement (yes vs no) & $-0.101(-0.188,-0.013)^{*}$ & $-0.194(-0.343,-0.046)^{*}$ \\
\hline
\end{tabular}

* p < 0.05. RF: rheumatoid factor; HAQ: Health Assessment Questionnaire; ESR: erythrocyte sedimentation rate; CRP: C-reactive protein.

femoral neck and total body ${ }^{7}$. Our study included patients with active disease and also those in remission; who are only seen infrequently. Overall, there was no association with current disease activity as assessed by ESR and CRP at the time of our study.

Previous studies suggested a greater degree of bone loss among those with functional impairment. Thus, higher Steinbrocker functional class in adolescence was associated with reduced adult $\mathrm{BMD}_{\mathrm{a}}$ at the femoral neck or lumbar spine $^{14}$ and hip ${ }^{13}$. Our data support these findings, demonstrating lower bone mass in those with higher HAQ scores. Our data are consistent also with previous studies that suggest that polyarticular disease is associated with a greater degree of bone loss than other disease subtypes ${ }^{13,14}$. We found also that those with extended oligoarticular disease had reduced bone mass at the hip ${ }^{13}$. The higher spine bone mass in those with enthesitis-related disease may perhaps reflect the presence of abnormal bone formation related to spondylitis.

Longterm oral corticosteroid treatment is known to be associated with low $\mathrm{BMD}_{\mathrm{a}}$ and fractures in patients with chronic diseases ${ }^{18,19}$. Some studies support an association between corticosteroid therapy and bone mass in JIA. Haugen, et al found duration of corticosteroid treatment was associated with low $\mathrm{BMD}_{\mathrm{a}}{ }^{7}$ and comparing T-scores, while Zak, et al found corticosteroid treatment for $>1$ year was associated with reduced $\mathrm{BMD}_{\mathrm{a}}{ }^{13}$. In contrast, French, et al found no association of reduced $\mathrm{BMD}_{\mathrm{a}}$ with corticosteroid treatment, although the number of patients treated with corticosteroids was low ${ }^{14}$. We found that those with a history of corticosteroid therapy had lower bone mass than those without, although there was no apparent association with duration of therapy. It is possible this may have been due to a lack of accurate recording of therapy in the medical record. Evidence of an association, however, does not imply causality and it is possible that the apparent association may have been confounded by disease severity.

Our results suggest that there is a reduction in bone mass in adults with a history of JIA and they are therefore likely to be at increased risk of fracture in later life. A metaanalysis of 11 prospective cohort studies $(90,000$ patient-years and 2000 fractures of any type) demonstrated that the risk of fracture in otherwise healthy adults appears to double for each $1 \mathrm{SD}$ decrease in $\mathrm{BMD}_{\mathrm{a}}{ }^{20}$. Thus, measures to optimize bone health in patients with JIA need to be considered, including modification of reversible risk factors and also optimizing function. In those with severe disease or those on longterm corticosteroids, bone densitometry should be considered an important component of routine clinical practice.

$\mathrm{BMD}_{\mathrm{a}}$ is reduced in some adults with JIA, particularly among those with more severe disease. These patients are at risk of the complications of osteoporosis in the future, including fragility fractures, and should be considered for preventive therapy. 


\section{ACKNOWLEDGMENT}

The authors thank Dr. Namita Kumar and Dr. Sarah Bartram, who were involved in the data collection.

\section{REFERENCES}

1. Kotaniemi A, Savolainen A, Kroger H, Kautiainen H, Isomaki H. Development of bone mineral density at the lumbar spine and femoral neck in juvenile chronic arthritis - a prospective one year followup study. J Rheumatol 1998;25:2450-5.

2. Lien G, Flato B, Haugen M, Vinje O, Sorskaar D, Dale K, et al. Frequency of osteopenia in adolescents with early-onset juvenile idiopathic arthritis: A long-term outcome study of one hundred five patients. Arthritis Rheum 2003;48:2214-23.

3. Lien G, Selvaag AM, Flato B, Haugen M, Vinje O, Sorskaar D, et al. A two-year prospective controlled study of bone mass and bone turnover in children with early juvenile idiopathic arthritis. Arthritis Rheum 2005;52:833-40.

4. Bianchi ML, Cimaz R, Galbiati E, Corona F, Cherubini R, Bardare $\mathrm{M}$. Bone mass change during methotrexate treatment in patients with juvenile rheumatoid arthritis. Osteoporos Int 1999;10:20-5.

5. Perez MD, Abrams SA, Loddeke L, Shypailo R, Ellis KJ. Effects of rheumatic disease and corticosteroid treatment on calcium metabolism and bone density in children assessed one year after diagnosis, using stable isotopes and dual energy $\mathrm{x}$-ray absorptiometry. J Rheumatol 2000;58:38-43.

6. Falcini F, Bindi G, Ermini M, Galluzzi F, Poggi G, Rossi S, et al. Comparison of quantitative calcaneal ultrasound and dual energy $\mathrm{X}$-ray absorptiometry in the evaluation of osteoporotic risk in children with chronic rheumatic diseases. Calcif Tissue Int 2000;67:19-23.

7. Haugen M, Lien G, Flato B, Kvammen J, Vinje O, Sorskaar D, et al. Young adults with juvenile arthritis in remission attain normal peak bone mass at the lumbar spine and forearm. Arthritis Rheum 2000;43:1504-10.

8. Kotaniemi A, Savolainen A, Kroger H, Kautiainen H, Isomaki H. Weight-bearing physical activity, calcium intake, systemic glucocorticoids, chronic inflammation, and body constitution as determinants of lumbar and femoral bone mineral in juvenile chronic arthritis. Scand J Rheumatol 1999;28:19-26.
9. Rooney M, Davies UM, Reeve J, Preece M, Ansell BM, Woo PM. Bone mineral content and bone mineral metabolism: changes after growth hormone treatment in juvenile chronic arthritis. J Rheumatol 2000;27:1073-81.

10. Brik R, Keidar Z, Schapira D, Israel O. Bone mineral density and turnover in children with systemic juvenile chronic arthritis. J Rheumatol 1998;25:990-2.

11. Murray KJ, Boyle RJ, Woo P. Pathological fractures and osteoporosis in a cohort of 103 systemic onset juvenile idiopathic arthritis patients [abstract]. Arthritis Rheum 2000;43 Suppl:S119.

12. Burnham JM, Shults J, Weinstein R, Lewis JD, Leonard MB. Childhood onset arthritis is associated with an increased risk of fracture: a population based study using the General Practice Research Database. Ann Rheum Dis 2006;65:1074-9.

13. Zak M, Hassager C, Lovell DJ, Nielsen S, Henderson CJ, Pedersen FK. Assessment of bone mineral density in adults with a history of juvenile chronic arthritis: a cross-sectional long-term followup study. Arthritis Rheum 1999;42:790-8.

14. French AR, Mason T, Nelson AM, Crowson CS, O'Fallon WM, Khosla S, et al. Osteopenia in adults with a history of juvenile rheumatoid arthritis. A population based study. J Rheumatol 2002;29:1065-70

15. Havelka S, Vavrincova P, Stepan J. Metabolic bone status in young women with juvenile chronic arthritis. J Rheumatol 1993;20 Suppl 37:14-6.

16. Petty RE, Southwood TR, Manners P, Baum J, Glass DN, Goldenberg $\mathrm{J}$, et al. International League of Associations for Rheumatology classification of juvenile idiopathic arthritis: second revision, Edmonton, 2001. J Rheumatol 2004;31:390-2.

17. Foster HE, Marshall N, Myers A, Dunkley P, Griffiths ID. Outcome in adults with juvenile idiopathic arthritis: a quality of life study. Arthritis Rheum 2003;48:767-75.

18. Sambrook P, Lane NE. Corticosteroid osteoporosis. Best Pract Res Clin Rheumatol 2001;15:401-13.

19. Kanis JA, Johansson H, Oden A, Johnell O, de Laet C, Melton LJ III, et al. A meta-analysis of prior corticosteroid use and fracture risk. J Bone Miner Res 2004;19:893-9.

20. Marshall D, Johnell O, Wedel H. Meta-analysis of how well measures of bone mineral density predict occurrence of osteoporotic fractures. BMJ 1996;312:1254-9. 